\title{
Analisis Implementasi Saturated Iron - Core Superconducting Fault Current Limiter pada Jaring Distribusi PT. PERTAMINA RU V BALIKPAPAN
}

\author{
Muhammad Nur Fattah, Margo Pujiantara, Heri Suryoatmojo \\ Jurusan Teknik Elektro, Fakultas Teknologi Industri, Institut Teknologi Sepuluh Nopember (ITS) \\ Jl. Arief Rahman Hakim, Surabaya 60111 Indonesia \\ e-mail:margo@ee.its.ac.id, suryomgt@ee.its.ac.id
}

\begin{abstract}
Abstrak - Pada studi ini akan dilakukan analisis hubung singkat pada sistem distribusi PT. PERTAMINA RU V. Analisis hubung singkat dilakukan pada bus utama PT. PERTAMINA RU V dengan rating $6,6 \mathrm{kV}$ dan melihat pada bus mana yang tidak mampu menahan besarnya arus gangguan karena adanya retrofit generator STG I-4 yang terhubung pada sistem kelistrikan PT. PERTAMINA RU V. Saat terjadi gangguan hubung singkat 3 fasa peak pada bus 2HT dan 3HT, rating bracing peak pada bus sebesar $78,75 \mathrm{kA}$ tidak mampu menahan arus gangguan sebesar 84,72 kA. Agar tidak terjadi kerusakan pada bus tersebut, maka diperlukan sebuah device pembatas arus gangguan yaitu Saturated Iron - Core Superconducting Fault Current Limiter (SISFCL). SISFCL dipasang pada satu incoming yang terhubung ke bus 2HT dimana pada incoming ini menyumbang arus kontribusi. Setelah dipasang SISFCL, nilai arus gangguan pada bus $2 \mathrm{HT}$ dan $3 \mathrm{HT}$ berkurang dari 84,72 kA menjadi 73,12 kA. Arus gangguan pada incoming yang dipasang SISFCL juga akan berkurang sehingga setting koordinasi proteksi untuk rele arus lebih juga akan berubah untuk itu diperlukan setting ulang pada beberapa rele. Setting ulang rele ditunjukkan pada kurva TCC ( Time Current Curve).
\end{abstract}

Kata Kunci-arus hubung singkat, koordinasi proteksi, kurva time current characteristic, rele arus lebih, SISFCL.

\section{PENDAHULUAN}

$\mathrm{P}_{\mathrm{n}}^{\mathrm{T}}$ T. PERTAMINA RU (Refinery Unit) V Balikpapan merupakan salah satu unit dari sektor usaha hilir yaitu pengolahan minyak yang dimiliki oleh PT. PERTAMINA (Persero). PT. PERTAMINA RU V berupaya untuk merevitalisasi dan meningkatkan kapasitas 6 unit kilang pengolahan minyak dalam proyek refinery development master plan Kilang Balikpapan, maka dilakukan retrofit di satu unit pembangkit steam turbine generator (STG I-4) sebesar 1x9 MW. Penambahan daya listrik pada sistem kelistrikan PT. PERTAMINA RU V agar kontinuitas pelayanan listrik dapat terjaga. Penambahan daya listrik yang dilakukan yaitu dengan melakukan retrofit di salah satu unit pembangkit steam turbine generator (STG I4) sebesar $9 \mathrm{MW}$ yang terhubung pada sistem. Tetapi dengan banyaknya generator pada sistem dan juga beban yang terpasang, memberikan dampak membuat kenaikan level arus gangguan yang semakin tinggi gangguan dapat merusak peralatan.

Salah satu jenis gangguan dalam sistem tenaga listrik yaitu gangguan hubung singkat. Gangguan ini sering terjadi pada sistem tenaga listrik dan menyebabkan rusaknya peralatan akibat nilai arus gangguan yang diakibatkan sangat tinggi. Agar arus gangguan tidak sampai menyebabkan penggantian peralatan pada sistem, maka arus gangguan hubung singkat harus diminimalisir sehingga nilainya dibawah dari level kemampuan peralatan yang ada dengan cara untuk memasang Saturated Iron - Core Superconducting Fault Current Limiter (SISFCL) pada sistem. Arus gangguan akan direduksi dengan impedansi dari inti SISFCL sehingga tidak akan merusak peralatan. Pemasangan SISFCL akan mempengaruhi koordinasi proteksi pada rele arus lebih, sehingga perlu dilakukan koordinasi ulang agar bisa mengetahui apakah sistem pengaman akan bekerja dengan baik atau tidak.

\section{SISTEM PENGAMAN DAN SATURATED IRON CORE SUPERCONDUCTING FAULT CURRENT LIMITER} (SISFCL)

\section{A. Gangguan Hubung Singkat}

Dalam operasi sistem tenaga listrik sering terjadi gangguan - gangguan yang menyebabkan terganggunya pelayanan tenaga listrik ke konsumen. Gangguan pada sistem tenaga listrik adalah segala macam kejadian yang menyebabkan kondisi pada sistem tenaga listrik menjadi abnormal atau arus yang mengalir dari satu konduktor ke ground atau ke konduktor lainya karena hubungan abnormal (termasuk arching) diantara keduanya. Beberapa penyebab gangguan pada sistem tenaga listrik yaitu : Adanya hewan dalam peralatan, overheating pada peralatan, tegangan Surja dan faktor alam lainya serta serta kerusakan isolasi karena usia dan lain sebagainya. Sifat gangguan ada yang sementara dan permanen. Gangguan hubung singkat diantaranya yaitu : hubung singkat 3 fasa, hubung singkat dua fasa, hubung singkat satu fasa ke tanah, dan hubung singkat dua fasa ke tanah [1].

\section{B. Akibat gangguan hubung singkat}

Akibat-akibat yang ditimbulkan dengan adanya gangguan hubung singkat tersebut antara lain :

- Rusaknya peralatan listrik yang berada dekat dengan gangguan yang disebabkan arus-arus yang besar, arus tak seimbang maupun tegangan-tegangan rendah.

- Berkurangnya stabilitas daya sistem tersebut.

- Terhentinya kontinuitas pelayanan listrik ke beban. 


\section{Saturated Iron - Core Superconducting Fault Current} Limiter (SISFCL)

SISFCL merupakan sebuah alat pengaman pada sistem distribusi tenaga listrik. SISFCL diciptakan karena kebutuhan akan energi listrik dengan penambahan daya tetapi peralatan seperti switchgear dan CB kapasitasnya tetap sehingga jika terjadi arus hubung singkat maka akan menyebabkan arus melebihi dari rating peralatan sehingga peralatan dapat terbakar.

SISFCL pada saat keadaan normal, switch pada rangkaian DC dalam keadaan close sehingga arus DC mengalir pada kumparan DC yang mengakibatkan kedua inti besi mengalami saturasi dan menjadikan medan $(\mathrm{H})$ besar, serta impedansi menjadi kecil seperti impedansi udara. Saat gangguan hubung singkat terdeteksi dalam waktu 1 mili detik, rangkaian kontrol akan mengirim sinyal ke switch kecepatan tinggi dan switch rangkaian DC akan terbuka dan mengakibatkan inti besi keluar dari kondisi saturasi dan mengecil. Energi megnetik atau kuat medan $(\mathrm{H})$ yang tersimpan dalam inti selama saturasi lalu dilepaskan melalui rangkaian pelepasan energi sehingga meningkatkan impedansi dari kumparan AC. Meningkatnya impedansi akan membatasi arus hubung singkat dalam waktu 5 mili detik.

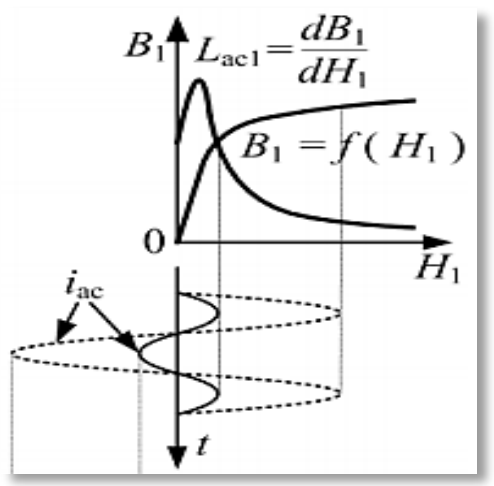

Gambar 1. Kurva karakteristik pembatas arus pada aktif SISFCL [2]

Dari gambar diatas didapatkan suatu persamaan yaitu:

$$
\mathrm{L}=\frac{\mathrm{dB}}{\mathrm{dH}}
$$

nilai $\mathrm{Z}_{\mathrm{SFCL}}$, sehingga didapatkan persamaan

$$
\mathrm{Z}_{\mathrm{sfcl}}=\frac{\mathrm{V}_{\mathrm{bus}}}{\sqrt{3}}\left[\frac{1}{\mathrm{Isc}_{\text {desire }}}-\frac{1}{\mathrm{Isc}_{\mathrm{system}}}\right]
$$

Dimana :

$\begin{array}{ll}\mathrm{V}_{\text {bus }} & =\text { rating tegangan bus SISFCL dipasang }(\mathrm{V}) \\ \mathrm{I}_{\mathrm{SC} \text { desire }} & =\text { nilai arus kontribusi resetting yang diinginkan } \\ & \text { yang lewat pada SISFCL }(\mathrm{A}) \\ \mathrm{I}_{\mathrm{SC} \text { system }} & =\text { nilai arus kontribusi existing yang lewat di } \\ & \text { saluran yang akan dipasang SISFCL }(\mathrm{A}) \\ \mathrm{Z}_{\mathrm{SFCL}} & =\text { nilai impedansi CLR yang diinginkan }(\Omega) \\ \mathrm{Z}_{\text {desire }} & =\text { nilai impedansi total }(\mathrm{CLR}+\text { existing }(\Omega) \\ \mathrm{Z}_{\text {system }} & =\text { nilai impedansi existing }(\Omega)\end{array}$

Besarnya nilai impedansi dipengaruhi oleh perubahan kerapatan flux (B) dan perubahan kerapatan kuat medan $(\mathrm{H})$. Setelah gangguan hilang, switch rangkaian DC akan kembali close dan arus DC akan mengalir kembali pada kumparan DC sehingga inti besi kembali saturasi dan menyebabkan impedansi menjadi kecil. Waktu recovery atau waktu dari gangguan ke normal kembali dibutuhkan waktu beberapa ratus mili detik, atau sekitar 800 mili detik $[3,4]$.

\section{Tujuan penggunaan SISFCL}

Tujuan implementasi SISFCL pada jaring distribusi PT. PERTAMINA RU V antara lain:

- Mereduksi biaya pembuatan atau pembelian peralatan seperti busbar, cb, dan lainnya.

- Mengatasi masalah arus hubung singkat pada switchgear.

- Puncak arus hubung singkat tidak akan pernah terjadi.

- Arus hubung singkat akan tereduksi pada saat kenaikan pertama.

\section{E. Skematik Rangkaian SISFCL}

Berikut adalah skematik rangkaian aktif SISFCL :

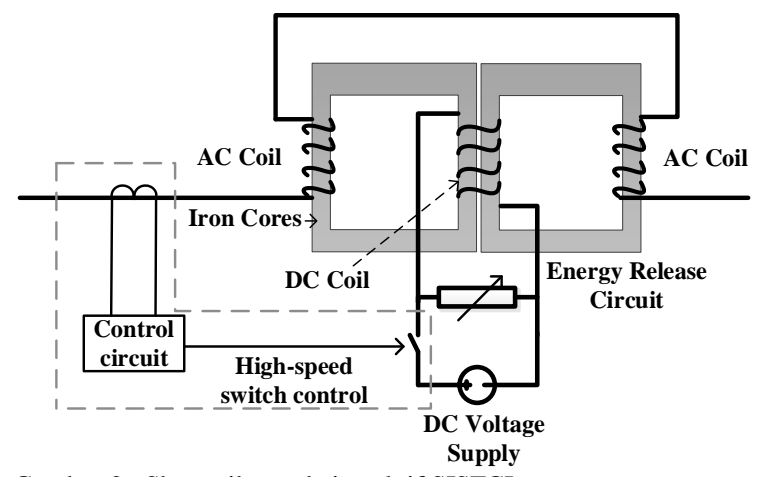

Gambar 2. Skematik rangkaian aktif SISFCL.

Keuntungan lain dari penggunaan SISFCL dibandingkan dengan air-core reaktor pembatas arus dan trafo tradisional yaitu : dari segi struktur dan fungsi, pada SISFCL tidak ada celah udara seperti trafo, tetapi fungsi dan penggunaanya seperti air - core reaktor pembatas arus. Dalam aplikasi pada grid dalam keadaan steady state atau keadaan normal, impedansi dalam SISFCL mendekati nol, dan saat ada gangguan maka impedansi SISFCL tinggi, beda dengan aircore reaktor yang memberi nilai impedansi tetap pada kondisi normal dan gangguan, sehingga menyebabkan jatuh tegangan dan rugi daya lebih besar.

\section{F. Rele Arus Lebih Waktu Terbalik (Invers Time)}

Dimana rele jenis ini mempunyai karakteristik waktu operasi yang berbanding terbalik terhadap arus gangguan. Semakin besar arus gangguan, semakin kecil waktu untuk rele memberikan sinyal agar pemutus tenaga membuka. Untuk pengaturan rele invers mengikuti standar British BS 142-1983 yaitu antara 1,05 - 1,4 $\mathrm{I}_{\text {set. }}$ Besaran pada rele invers yang lain yaitu menghitung nilai time dial. Dalam PT. PERTAMINA RU V digunakan rele salah satunya ALSTOM P142, dengan rumus $t$ sebagai berikut :

$$
\mathrm{t}=\left[\frac{\mathrm{A}}{\left(\mathrm{I}^{\mathrm{B}}-1\right)}\right] \times \mathrm{tD}
$$

Dimana :

$$
\begin{array}{ll}
\mathrm{t} & =\text { waktu operasi } \\
\mathrm{tD} & =\text { time dial } \\
\mathrm{A}, \mathrm{B} & =\text { besaran berdasarkan jenis rele } \\
\mathrm{I} & =\frac{\mathrm{I}_{\mathrm{f}}}{\mathrm{I}_{\mathrm{set}}}
\end{array}
$$

Beberapa besaran dari rele ALSTOM P142 yang digunakan dalam perhitungan disajikan dalam tabel berikut : 
Tabel 1

Data Nilai Koefisien rele ALSTOm p142 (IEC curve)

\begin{tabular}{cccc}
\hline \hline Koefisien & $\begin{array}{c}\text { Extremely } \\
\text { Inverse }\end{array}$ & $\begin{array}{c}\text { Very } \\
\text { Inverse }\end{array}$ & Inverse \\
\hline A & 80 & 13,5 & 0,14 \\
B & 2 & 1 & 0,02 \\
\hline \hline
\end{tabular}

\section{G. Rele Arus Lebih Seketika (Instantaneous)}

Karaktristik rele jenis ini adalah karakteristik rele yang paling sederhana dimana jangka waktu kerja rele mulai dari pick up sampai rele bekerja sangat singkat tanpa adanya waktu tunda rele. syarat setting arus pada rele arus lebih dapat dirumuskan sebagai berikut :

$$
(1,05-1,4) \mathrm{I}_{\mathrm{FL}}<\mathrm{I}_{\mathrm{set}}<0,8 \mathrm{I}_{\mathrm{sc} \min }
$$

\section{SISTEM KELISTRIKAN PT. PERTAMINA RU V}

\section{A. Sistem Kelistrikan PT. PERTAMINA RU V}

Sistem kelistrikan PT. PERTAMINA RU V memiliki dua wilayah Power Plant yaitu Power Plant I (PP1) di Kilang 1 dan Power Plant II (PP2) di Kilang 2. Berikut adalah single line diagram keseluruhan sistem kelistrikan PT PERTAMINA RU V sesuai pada Gambar 3.2. Pada PP1 terdapat 5 pembangkit STG yaitu STG 1-3, STG 1-4, STG 15, STG 1-5A, STG 1-6 sedangkan pada PP2 terdapat 4 pembangkit STG yaitu STG 2-1, STG 2-2, STG 2-3, STG 24. Pembangkit-pembangkit inilah yang melayani kebutuhan suplai daya ke beban-bebannya. Namun PT. PERTAMINA RU V berencana untuk meningkatkan kapasitas produksi demi memenuhi target yang akan dicapai. Kondisi existing hingga saat ini hanya dioperasikan enam pembangkit STG yang beroperasi sejumlah 64.8MW. Sehingga PT. PERTAMINA RU V melakukan retrofit pada pembangkit STG I-4 sehingga total pembangkitan setelah STG I-4 di retrofit sebesar 73.8 MW. PT. PERTAMINA RU V memiliki 3 rating tegangan yaitu $6,6 \mathrm{kV}, 33 \mathrm{kV}$ dan $0,38 \mathrm{kV}$.

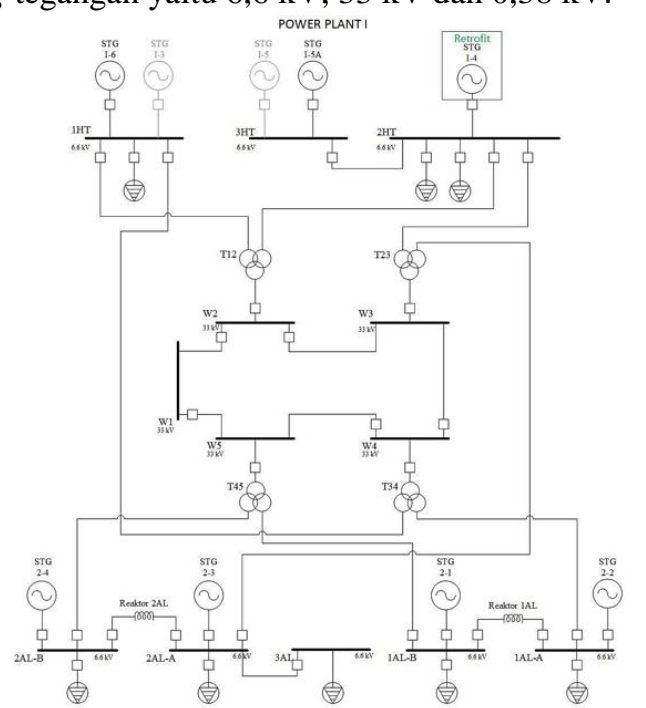

Gambar 3 Single Line Diagram PT. PERTAMINA RU V Balikpapan

\section{B. Sistem Pembangkitan Tenaga Listrik PT. PERTAMINA $R U V$}

PT. PERTAMINA RU V memiliki sembilan unit generator untuk menyuplai sistem kelistrikannya. Jenis generator untuk pembangkitan pada PT. PERTAMINA RU
V yaitu sembilan generator jenis STG (Steam Turbine Generator). Dalam operasi normal, PT. PERTAMINA RU V mengoperasikan 6 generator. Rincian data generator ditunjukkan pada Tabel 2:

Tabel 2.

Data pembangkit tenaga listrik

\begin{tabular}{|c|c|c|c|c|c|}
\hline Lokasi & No & ID Unit & $\begin{array}{c}\text { Tegangan } \\
\text { (kV) }\end{array}$ & $\begin{array}{c}\text { Kapasitas } \\
\text { (MW) }\end{array}$ & Keterangan \\
\hline \multirow{5}{*}{$\begin{array}{l}\text { Power } \\
\text { Plant } 1\end{array}$} & 1 & STG 1-3 & 6.6 & 7.5 & Out \\
\hline & 2 & STG 1-4 & 6.6 & 9 & ${ }^{*}$ Retrofit \\
\hline & 3 & STG 1-5 & 6.6 & 9 & Out \\
\hline & 4 & STG 1-5A & 6.6 & 9 & In \\
\hline & 5 & STG 1-6 & 6.6 & 9 & In \\
\hline \multicolumn{4}{|c|}{ Total } & 43.5 & \\
\hline \multirow{4}{*}{$\begin{array}{l}\text { Power } \\
\text { Plant } 2\end{array}$} & 1 & STG 2-1 & 6.6 & 8.4 & In \\
\hline & 2 & STG 2-2 & 6.6 & 12.8 & In \\
\hline & 3 & STG 2-3 & 6.6 & 12.8 & In \\
\hline & 4 & STG 2-4 & 6.6 & 12.8 & In \\
\hline \multicolumn{4}{|c|}{ Total } & 46.8 & \\
\hline \multicolumn{4}{|c|}{ Total PP1 + PP2 } & 90.3 & 73.8 \\
\hline
\end{tabular}

C. Sistem Distribusi Tenaga Listrik PT. PERTAMINA RU V Jaringan sistem distribusi pada PT. PERTAMINA RU

V Balikpapan memiliki 3 konfigurasi yaitu :

-Radial murni

-Selective Secondary Radial

-Ring

D. Jumlah Total Pembangkitan, Pembebanan, dan Demand. Summary dari jumlah total pembangkitan, pembebanan, dan demand dari PT. PERTAMINA RU V Balikpapan dapat dilihat pada Tabel 3:

Tabel 3.

Data jumlah total pembangkitan, pembebanan, dan Demand pada PT. PERTAMINA RU V Balikpapan.

\begin{tabular}{|l|c|c|c|c|}
\hline & MW & MVar & MVA & \%PF \\
\hline Source (swing bus) & 28.45 & 18.94 & 34.18 & $83.23 \mathrm{Lag}$ \\
\hline Source (non swingbus) & 34.00 & 19.65 & 39.27 & $86.58 \mathrm{Lag}$ \\
\hline Total Demand & 62.450 & 38.60 & 73.41 & $85.06 \mathrm{Lag}$ \\
\hline Total Motor Load & 53.372 & 32.53 & 62.50 & $85.39 \mathrm{Lag}$ \\
\hline Total Static Load & 8.819 & 5.5 & 10.43 & $84.51 \mathrm{Lag}$ \\
\hline
\end{tabular}

\section{SIMULASI DAN ANALISIS PADA PT. PERTAMINA RU V}

\section{A. Analisis Kemampuan Peralatan}

Analisis kemampuan peralatan dengan hubung singkat maksimum 3 fasa $1 / 2$ cycle untuk melihat kondisi bus ketika terjadi gangguan maksimum atau dalam fase sub-transien (momentary) saat kondisi awal atau eksisting. Gangguan diberikan pada bus utama dengan rating tegangan $6,6 \mathrm{kV}$ dan dilihat berapa nilai arus asymmetry peak (nilai arus puncak yang mengandung komponen DC) apakah nilai gangguan tersebut melebihi kapasitas kemampuan bus sesaat dalam menahan arus hubung singkat maksimum atau bracing pada rating bus tersebut.

Tabel 4.

Data kemampuan bus

\begin{tabular}{ccccc}
\hline \hline No & Rating & $\begin{array}{c}\text { Bracing } \\
\text { Peak bus } \\
\text { ID }\end{array}$ & $\begin{array}{c}\text { Asymmetry arus } \\
\text { gangguan } \\
\text { maksimal 3 fasa } \\
1 / 2 \text { cycle }\end{array}$ \\
\hline 1 & 1HT & 6,6 & 78,75 & 71,60 \\
2 & 2HT & 6,6 & 78,75 & 84,72 \\
3 & 3HT & 6,6 & 78,75 & 84,72 \\
\hline \hline
\end{tabular}


Berdasarkan pada Tabel 4 bus 2HT dan 3HT dalam keadaan kritis dikarenakan arus hubung singkat melebihi rating device capability atau bracing peak. Sehingga dibutuhkan pemasangan SISFCL sebagai pembatas arus.

Selanjutnya adalah menentukan dimana letak SISFCL agar mampu membatasi arus gangguan secara maksimal. Peletakan SISFCL yaitu dipasang pada incoming yang melewatkan arus kontribusi dari generator STG I-4 bus 2HT. Untuk nilai kontribusi pada bus 2HT bisa dilihat dalam Gambar 4 berikut :

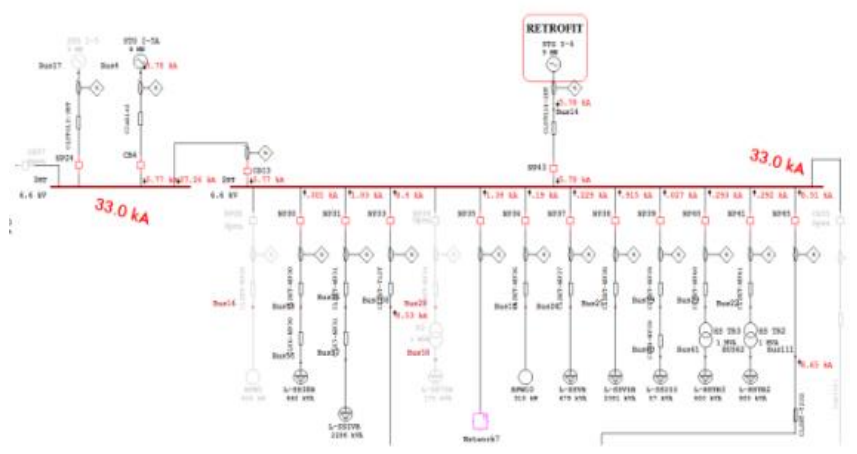

Gambar 4. Nilai arus kontribusi pada bus $2 \mathrm{HT}$ sebelum pemasangan SISFCL

Arus kontribusi yang akan direduksi ketika terjadi hubung singkat berada pada incoming yang menghubungkan STG I-4 dengan bus 2HT. SISFCL diletakkan pada satu incoming tersebut agar arus gangguan dapat direduksi dengan baik. Pada software simulasi, SISFCL dimodelkan dengan rekator yang terhubung ke swtch. Untuk mengetahui nilai impedansi dari SISFCL, maka dilakukan perhitungan impedansi untuk SISFCL, yaitu :

$$
\begin{aligned}
& \mathrm{Z}_{1}=\frac{\mathrm{V}_{\mathrm{bus}}}{\sqrt{3}}\left[\frac{1}{\text { Isc }_{\text {desire }}}-\frac{1}{\mathrm{Isc}_{\text {system }}}\right] \\
& \mathrm{Z}_{1}=\frac{6600}{\sqrt{3}}\left[\frac{1}{1400}-\frac{1}{5770}\right] \\
&=2,061 \Omega
\end{aligned}
$$

B. Analisis Kemampuan Bus Setelah Pemasangan SISFCL Setelah pemasangan SISFCL pada feeder yang telah dibahas diatas, maka selanjutnya yaitu analisis ulang kemampuan bus dalam menahan arus gangguan. Bus $2 \mathrm{HT}$ dengan diberi gangguan maksimal 3 fasa $1 / 2$ cycle dan dilihat nilai asymmetry peak total bus dan arus kontribusi

Tabel 5.

Data perbandingan kemampuan bus $2 \mathrm{HT}$ dengan $\mathrm{I}_{\mathrm{SC}}$ maksimum 3 fasa pada kondisi $1 / 2$ cycle sebelum dan sesudah dipasang SISFCL

\begin{tabular}{cccccc}
\hline \hline \multirow{2}{*}{ No } & \multirow{2}{*}{$\begin{array}{c}\text { Rating } \\
\text { bus } \\
(\mathrm{kA})\end{array}$} & $\begin{array}{c}\text { Bracing } \\
\text { Peak } \\
\text { bus } \\
(\mathrm{kA})\end{array}$ & $\begin{array}{c}\text { Asymmetry arus gangguan } \\
\text { maksimal 3 fasa 1/2 cycle } \\
\text { Tanpa }\end{array}$ & $\begin{array}{c}\text { Dengan } \\
\text { SISFCL }\end{array}$ & SISFCL \\
\hline 1 & 2HT & 6,6 & 78,75 & 84,72 & 73,17 \\
2 & 3HT & 6,6 & 78,75 & 85,72 & 73,17 \\
\hline \hline
\end{tabular}

Untuk nilai arus kontribusi pada Bus 2HT setelah pemasangan SISFCL sebagai berikut :

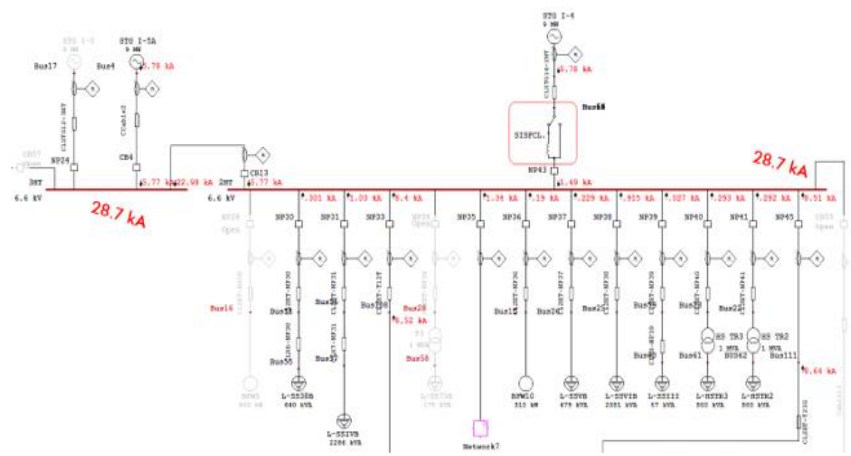

Gambar 5. Nilai arus kontribusi pada bus 2HT sesudah pemasangan SISFCL

Nilai arus kontribusi pada incoming yang dipasang SISFCL berkurang. Untuk incoming yang terhubung ke bus 2HT arus kontribusi yang lewat SISFCL dari 5,77 kA direduksi menjadi 1,49 kA., bus 2HT dan 3HT statusnya menjadi kondisi aman atau tidak kritis lagi ketika ada hubung singkat.

\section{Cara Kerja Saturated Iron - Core Superconducting}

Fault Current Limiter (SISFCL)

Pada saat kondisi gangguan, arus hubung singkat sebelum pemasangan SISFCL terlihat pada Gambar 6 gelombang biru, sedangkan grafik hubung singkat setelah dipasang SISFCL terlihat pada gelombang berwarna merah. Saat terjadi gangguan pada 1 millisecond, terjadi perbedaan arus pada kondisi normal dan arus saat kondisi gangguan. SISFCL akan mendeteksi adanya perbedaan arus yang mengalir pada feeder. Rangkaian kontrol akan memerintahkan switch rangkaian DC untuk membuka, sehingga inti besi keluar dari kondisi saturasi dan kuat medan $(\mathrm{H})$ mengecil sedangkan impedansi meningkat pada kumparan AC. Selanjutnya pada saat 5 millisecond arus gangguan yang lewat kumparan AC pada SISFCL akan diredam, dan selebihnya dilewatkan menuju sistem dengan nilai yang lebih kecil dari nilai arus gangguan asalnya. Untuk memodelkan bentuk gelombang arus hubung singkat 3 fasa $1 / 2$ cycle pertama pada bus $2 \mathrm{HT}$ digunakan metode transien IEC 61361.

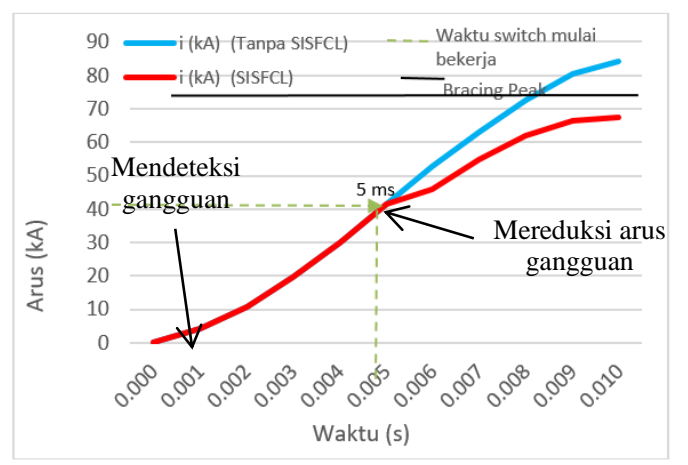

Gambar 4. Analisis Cara Kerja SISFCL saat membatasi arus gangguan

Untuk menurunkan arus hubung singkat agar peralatan aman dari arus yang melebihi kapasitas rating peralatan maka pemasangan SISFCL merupakan cara yang tepat sehingga arus puncak hubung singkat dapat direduksi. Bentuk gelombang $1 / 2$ cycle pertama arus hubung singkat pada bus 2HT dapat dilihat pada Gambar 7. 
Setelah 5 millisecond, nilai arus gangguan yang direduksi oleh SISFCL turun sampai dibawah batas kemampuan bus 2HT sehingga arus gangguan tidak sampai merusak bus tersebut. SISFCL mencapai kondisi recovery atau kembali ke keadaan normal dengan membutuhkan waktu 800 millisecond atau 0,8 detik. Switch rangkaian DC akan kembali close dan arus DC kembali mengalir pada kumparan DC sehingga nilai kuat medan $(\mathrm{H})$ akan naik dan nilai impedansi turun sampai seperti impedansi udara.

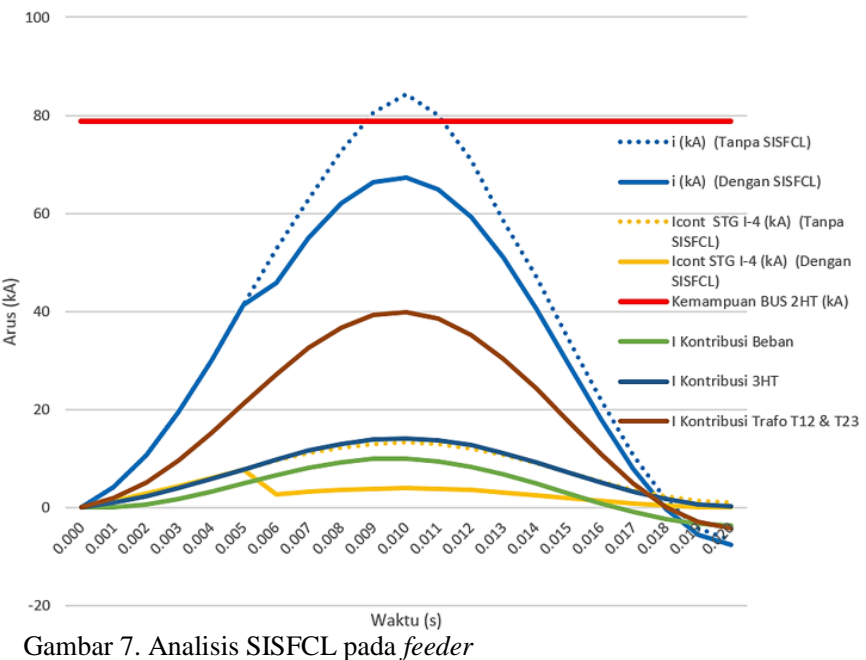

\section{Koordinasi Proteksi Tipikal 3}

Sistem pengaman pada tipikal 3 terdiri dari rele RNP45 dan rele RNP43. Koordinasi tipikal 3 mulai dari primer trafo T23 sampai generator STG-4. Rele RNP45 melindungi sisi primer trafo T23 dan Rele RNP43 melindungi generator STG I-4 dan pada sisi SISFCL.

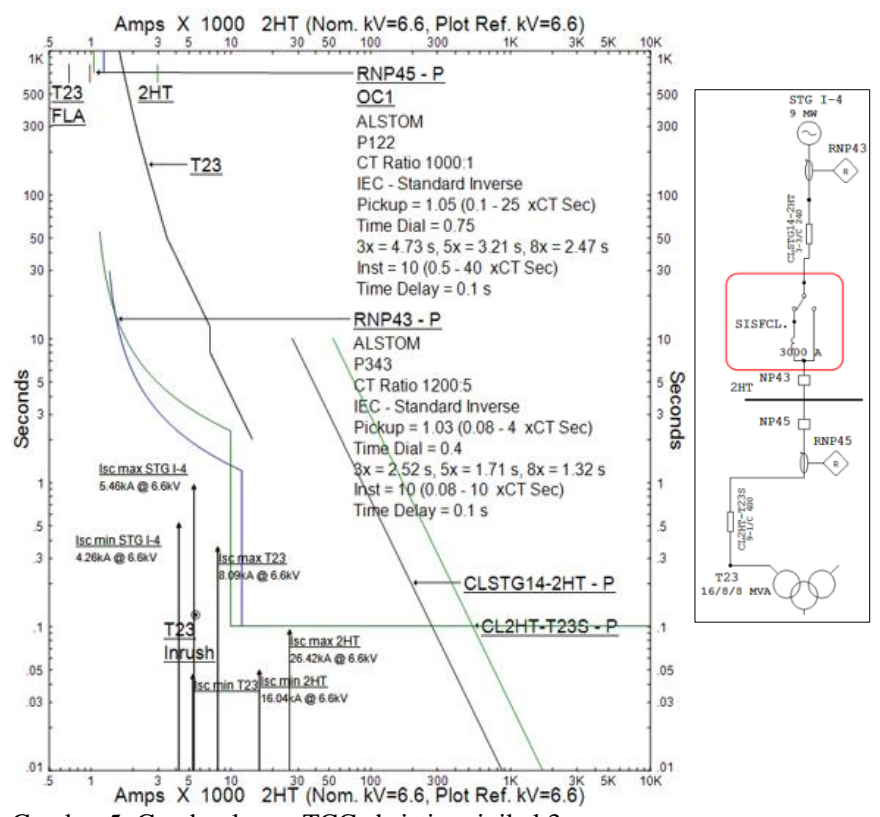

Gambar 5. Gambar kurva TCC eksisting tipikal 3

Kondisi eksisting tipikal 3 :

- Sistem koordinasi proteksi rele arus lebih pada tipikal 3 sebelum adanya pemasangan SISFCL sudah baik, namun masih perlu dilakukan koordinasi proteksi ulang pada rele rele di tipikal 3 agar kecepatan dan sensitifitas rele dalam bekerja semakin baik.
Untuk perhitungan resetting ulang koordinasi rele proteksi tipikal 3 perhitunganya sebagai berikut :

\section{$\square \underline{\text { Rele RNP45 }}$}

Manufacturer

Model

: ALSTOM

Curve Type

: P122

CT Ratio

:Standard Inverse (IEC)

Isc min kontribusi

$: 1000 / 5$

Isc max kontribusi

$: 15790 \mathrm{~A}$

FLA Lump

$: 23290 \mathrm{~A}$

: $699.8 \mathrm{~A}$

\section{Time Overcurrent Pickup}

$1,05 \times$ Trafo T23 $\leq$ Iset $\leq 1,3 \times$ FLA Trafo T23

$1,05 \times 699.8 \leq$ Iset $\leq 1,3 \times 699.8$

$734.79 \leq$ Iset $\leq 909.74$

$\frac{734.79}{1000}$ In $\leq$ Tap $\leq \frac{909.74}{1000}$ In

$0,734 \mathrm{In} \leq$ Tap $\leq 0,909$ In

Dipilih Tap $=0,85$ In

$$
\text { Iset }=0,85 \times 1000=850 \mathrm{~A}
$$

\section{$\underline{\text { Time Dial }}$}

$\mathrm{t}=\frac{0,14}{\left[\left(\frac{\mathrm{I}}{\mathrm{Iset}}\right)^{0,02}-1\right]} \times \mathrm{Td}$

Dipilih waktu operasi $(\mathrm{t})=0,3$ detik

$\mathrm{t}=\frac{0,14}{\left[\left(\frac{\text { Isc max Bus } 2 \mathrm{HT}}{\text { Iset }}\right)^{0,02}-1\right]} \times \mathrm{Td}$

$\mathrm{Td}=\frac{\mathrm{t} \cdot\left[\left(\frac{\text { Isc max Bus 2HT }}{\text { Iset }}\right)^{0,02}-1\right]}{0,14}$

$\mathrm{Td}=\frac{0,3 \cdot\left[\left(\frac{23290}{850}\right)^{0,02}-1\right]}{0,14}$

$\mathrm{Td}=0,146$

Dipilih Td $=0,15$

\section{Instantaneous Pickup}

$\mathrm{I}_{\text {set }} \leq 0,8 \times$ Isc min kontribusi

$\mathrm{I}_{\text {set }} \leq 0,8 \times 15790$

$\mathrm{I}_{\text {set }} \leq 12832$

Tap $\leq \frac{12832}{1000}$ In

$$
\leq 12.832 \text { In }
$$

Dipilih Tap $=2,32$ In (Range 0.08In -: 32In,step 0.01 In)

$$
\mathrm{I}_{\mathrm{set}}=2,32 \times 1000=2320 \mathrm{~A}
$$

Time delay

Dipilih time delay 0,5 detik

\section{$\square$ Rele RNP43}

Manufacturer

Model

: ALSTOM

Curve Type

CT Ratio

: P343

Isc min kontribusi

:Standard Inverse (IEC)

Isc max kontribusi

: $1200 / 5$

FLA Lump

: $15790 \mathrm{~A}$

: $23290 \mathrm{~A}$

: $984.1 \mathrm{~A}$

Time Overcurrent Pickup

$1,05 \times$ FLA STG I-5A $\leq$ Iset $\leq 1,3 \times$ FLA STG I-5A 
$1,05 \times 984.1 \leq$ Iset $\leq 1,3 \times 984.1$

$1033.305 \leq$ Iset $\leq 1279.33$

$\frac{1033.305}{1200}$ In $\leq$ Tap $\leq \frac{1279.33}{1200}$ In

0.86 In $\leq$ Tap $\leq 1.06$ In

Dipilih Tap $=0,9$ In

$$
\text { Iset }=0,9 \times 1200=1080 \mathrm{~A}
$$

$\frac{\text { Time Dial }}{\mathrm{t}=\frac{0,14}{\left[\left(\frac{\mathrm{I}}{\mathrm{Iset}}\right)^{0,02}-1\right]}} \times \mathrm{Td}$
Dipilih waktu opera

Dipilih waktu operasi $(\mathrm{t})=0,7$ detik

$\mathrm{t}=\frac{0,14}{\left[\left(\frac{\text { Isc max Bus 2HT }}{\text { Iset }}\right)^{0,02}-1\right]} \times \mathrm{Td}$

$\mathrm{Td}=\frac{\mathrm{t} \cdot\left[\left(\frac{\text { Isc max Bus 2HT }}{\text { Iset }}\right)^{0,02}-1\right]}{0,14}$

$\mathrm{Td}=\frac{0,7 \cdot\left[\left(\frac{23290}{1080}\right)^{0,02}-1\right]}{0,14}$

$\mathrm{Td}=0,31$

Dipilih Td =0,31

\section{Instantaneous Pickup}

$\mathrm{I}_{\mathrm{set}} \leq 0,8 \times$ Isc min kontribusi

$\mathrm{I}_{\text {set }} \leq 0,8 \times 15790$

$\mathrm{I}_{\text {set }} \leq 12832$

Tap $\leq \frac{12832}{400}$ In

$\leq 32.08 \mathrm{In}$

Dipilih Tap $=3$ In (Range 0.08In -: 32In,step 0.01 In) $\mathrm{I}_{\text {set }}=3 \times 400=1200 \mathrm{~A}$

Time delay

Dipilih time delay 0,7 detik

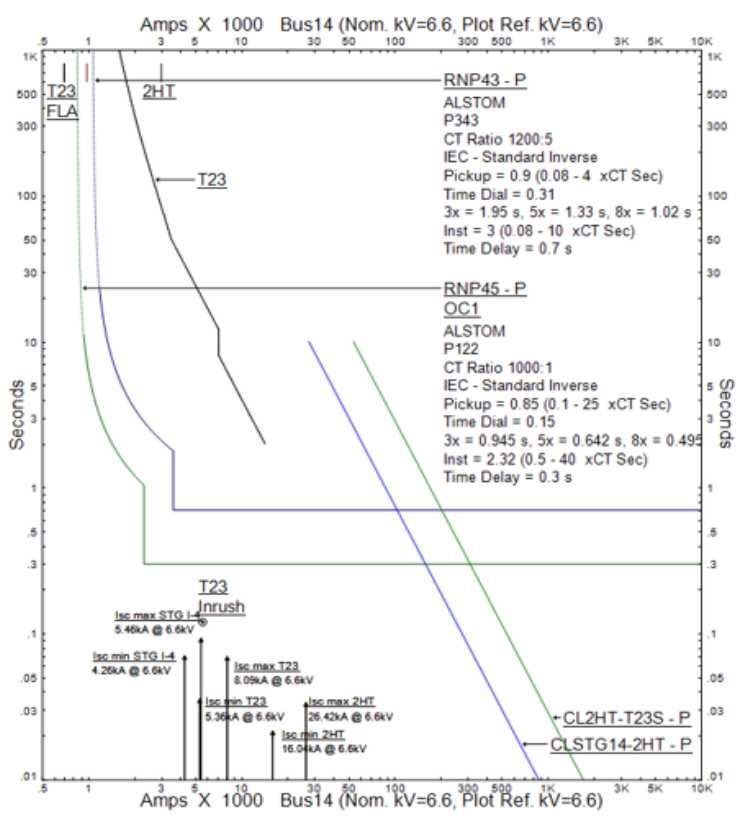

Gambar 5. Gambar kurva TCC resetting tipikal 3

Dari hasil resetting rele pengaman pada tipikal 3 diatas, dan dari plot TCC didapatkan analisis sebagai berikut:
- Dengan memperkecil time dial maka waktu trip CB juga semakin cepat dan sesuai dengan grading waktu yang diinginkan.

- Kecepatan rele akan semakin baik.

Tabel 6.

Perbandingan setting rele arus lebih sebelum dan sesudah pemasangan SISFCL pada koordinasi tipikal 3

\begin{tabular}{|c|c|c|c|c|c|}
\hline \multirow{2}{*}{ ID Rele } & \multirow{2}{*}{ CT Ratio } & \multicolumn{4}{|c|}{ Setting } \\
\hline & & \multicolumn{2}{|c|}{ Existing } & \multicolumn{2}{|c|}{ Resetting } \\
\hline \multirow{8}{*}{ RNP45 } & \multirow{8}{*}{$1200 / 5$} & Pickup & & Pickup & \\
\hline & & Lowset & 1,05 & Lowset & 0,85 \\
\hline & & Time & 075 & Time & 0.15 \\
\hline & & Dial & & Dial & \\
\hline & & Pickup & 10 & Pickup & 2,32 \\
\hline & & Highset & 10 & Highset & 2,52 \\
\hline & & Time & 0,1 & Time & 0,3 \\
\hline & & Delay & 0,1 & Delay & \\
\hline \multirow{7}{*}{ RNP43 } & \multirow{7}{*}{$1000 / 5$} & Pickup & & Pickup & \\
\hline & & Lowset & 1,03 & Lowset & 0,9 \\
\hline & & Time & 0.4 & Time & 031 \\
\hline & & Dial & 0,4 & Dial & 0,31 \\
\hline & & Pickup & 10 & Pickup & 3 \\
\hline & & Highset & 10 & Highset & \\
\hline & & $\begin{array}{l}\text { Time } \\
\text { Delay }\end{array}$ & 0,1 & $\begin{array}{l}\text { Time } \\
\text { Delay }\end{array}$ & 0,7 \\
\hline
\end{tabular}

\section{KESIMPULAN}

Berdasarkan analisis implementasi SISFCL (Saturated Iron - Core Superconducting Fault Current Limiter) pada jaring distribusi PT. PERTAMINA RU V, maka bisa diambil beberapa kesimpulan sebagai berikut :

1. Arus Hubung singkat 3 fasa yang melebihi dari kapasitas eksisting switchgear terjadi pada bus 2HT dan 3HT, yakni diatas rating nilai bracing peak sebesar $78.75 \mathrm{kA}$ maka membutuhkan pembatas arus yaitu SISFCL.

2. Pemasangan SISFCL biasanya dipasang pada feeder yang melewatkan arus kontribusi terbesar tetapi untuk pemasangan SISFCL di Kilang I dipasang pada incoming dari generator STG I-4 menuju bus 2HT. Pertimbangan SISFCL tidak ditempatkan pada feeder yang menuju trafo T23 dikarenakan jika CB NP45 trip atau tidak mendapatkan daya yang disebabkan oleh load shedding atau gangguan hubung singkat maka penempatan tersebut kurang ideal sehingga SISFCL akan dipasang pada incoming dari generator STG I-4 yang terhubung ke 6,6 kV BUS-2HT.

3. Pemasangan SISFCL dapat mereduksi arus gangguan pada bus $2 \mathrm{HT}$ yang semula $84.72 \mathrm{kA}$ peak menjadi $73.179 \mathrm{kA}$ peak. Sehingga peralatan pada bus 2HT aman.

4. SISFCL bekerja mereduksi arus gangguan memanfaatkan keadaan saturasi inti besi dengan nilai impedansi yang tinggi. Saat normal, nilai impedansi SISFCL kecil dan mendekati nol, kuat medan $(\mathrm{H})$ tinggi. Saat gangguan, kuat medan $(\mathrm{H})$ akan turun dan nilai impedansi akan naik untuk mereduksi arus gangguan. SISFCL mendeteksi adanya gangguan hubung singkat saat 0,1 detik, mulai mereduksi arus gangguan saat 0,5 detik dan kembali ke keadaan recovery saat 0.8 detik. 


\section{DAFTAR PUSTAKA}

[1] IEEE Std 551 $1^{\mathrm{TM}}$ - 2006, “IEEE Recommended Practice for Calculating Short-Circuit Currents in Industrial and Commercial Power Systems", The Institute of Electrical and Electronics Engineers, Inc., New York, Ch. 2, 2006.

[2] Li Bin, "Application Studies on the Active SISFCL in Electric Transmission System and its Impact on Line Distance Protection", IEEE Transactions on Applied Superconductivity, 2013.

[3] Hong Hui, "DC Magnetization System for a 35 kV/90 MVA Superconducting Saturated Iron-Core Fault Current Limiter", IEEE Transactions on Applied Superconductivity, Vol. 19, No. 3, June 2009.

[4] Wang Haizhen, "Saturated Iron Core Superconducting Fault Current Limiter", International Conference on Electric Power Equipment (IEEE) - Switching Technology - Xi'an - China, 1st 2011. 